\title{
Une enzootie pestique cryptogénétique sur des phacochères en captivité à Bamako (Soudan français)
}

\author{
par Ph. HILSONT et Ch. BOURDEREAU
}

Le parc zoologique de l'Institut français d'Afrique noire, installé à Bamako sur les pentes de la colline de Koulouba, entretient, parmi de nombreuses espèces sauvages, un troupeau de 15 phacochères dans un vaste enclos rocailleux bien grillagé.

Le 2 février 1954, le cadavre d'un de ces phacochères est présenté à la clinique de l'École des Assistants d'Élevage de Bamako. L'autopsie révèle un éclatement esquilleux du fémur, dû à un traumatisme violent, et la mort est attribuée à l'hémorragie crurale consécutive.

Quelques jours plus tard, le 8 février, un second cadavre arrive aux fins d'autopsie : on observe une violente congestion diffuse de la muqueuse stomacoduodénale, de teinte lie-de-vin, sans trace d'ulcérations. Le foie est hypertrophié, congestionné mais par ailleurs aucun signe de septicémie générale A titre de confirmation, le cadavre étant dans un état de remarquable fraicheur, une hémoculture du sang du cour est pratiquée, qui par la suite devait s'avérer négative.

Cette dernière mortalité fut imputée à un accident d'origine alimentaire, l'enquête ayant rèvélé que l'effectif était nourri, d'une part, de mil et d'herbe fraiche contre lesquels aucune suspicion ne pourrait être élevée et, d'autre part, de déchets de table provenant d'un établissement scolaire de la ville. Envisageant la possibilité d'une altération de ces déchets, nous conseillons de redresser le régime alimentaire du troupeau en éliminant toutes les substances susceptibles de subir une fermentation.

Le 11 février au matin, un nouveau malade nous est signalé et nous nous rendons au parc zoologique en vue de procéder à son examen.

Après une poursuite mouvementée, le phacochère est capturé, solidement ficelé, et nous pouvons l'examiner à loisir. La muqueuse bucale présente cette fois d'importantes desquamations à tendance ulcereuse; les conjonctives sont congestionnées et un fort larmoiement ravine le chanfrein; on note enfin une diarrhée sanguinolente et une température de $40^{\circ} 3$.

Quelques heures plus tard l'animal succombe et, à l'autopsie, apparaissent de grosses lésions d'entérite hémorragique avec plaques violacées aux abords de la valvule iléo-cæcale, sans toutefois d'ulcérations. Une myéloculture à partir d'un' os long devait s'avérer ultérieurement négative.

L'hypothèse d'une infection pestique ne fait plus aucun doute, mais nous inclinons plutôt en faveur de la peste bovine, d'une part en raison du manque de lésions caractéristiques de peste porcine, et surtout en considération des probabilités épidémiologiques.

A partir de ce moment, l'évolution se précipite. Le 13 février, un couple de malades nous est présenté avec desquamations buccales, conjonctivite, larmoiement et diarrheee. Chacun reçoit sous 'la peau' $100 \mathrm{~cm}^{3}$ de sérum antipestique bovin, mais cette intervention se révèle impuissante à enrayer l'évolution inexorable de la maladie : les deux malades succombent peu de temps après.

Le reste de l'effectif est toujours en liberté, il se dérobe avec vivacité aux tentatives de capture, mais déjà un examen attèntif permet de déceler sur la plupart des sujets une demarche gënée, parfois chancelante. tandis que d'autres se réfugient volontiers dans les anfractuosités rocheuses.

Il devient évident que la totalité de ce troupeau est sous le coup d'une incubation avancee, et ceci ne devait pas tarder à se vérifier par la cadence accélérée à laquelle succombèrent désormais les phacochères.

Les 9 derniers moururent à brève échéance, porteurs des mêmes lésions nécropsiques. Quant au $15^{\mathrm{e}}$ il parvient à s'enfuir en franchissant un grillage de 1 m 65 de hauteur, mais il est douteux qu'il ait pu survivre longtemps.

Ces 15 animaux (10 femelles et 5 mâles) avaient été introduits dans le jardin zoologique au mois d'août 1952.

L'effectif ne comportait que des adultes, les portées successives ayant été dévorées par les parents.

Les premieres victimes de la peste furent les femelles, tandis que les mâles, sans doute plus résistants, ne succombèrent qu'après. 
Il est intéressant de noter que, jusqu'à l'article de la mort, les malades ont fait preuve d'une grande vigueur (nous en fimes l'expérience lors de nos tentatives d'approche) et leur agonie fut très breve.

Toutes les autopsies pratiquées ont révélé des sujets en bon état d'entretien, sans amaigrissement ni marasme.

\section{DIAGNOSTIC EXPÉRIMENTAL}

Il était intéressant d'établir un diagnostic différenliel entre la peste bovine et la peste porcine. Le protocole expérimental établi à cet effet a été le suivant :

Le 15 février, à partir d'un cadavre frais, il est procédé à l'inoculation de 5 taurillons (2 taurins et 3 7ébius)

1 taurin et l zébu reçoivent du broyat de rate en sérum physiologique.

I taurin et 2 zébus reçoivent du sang du cœeur citraté. Les résultats de l'épreuve furent les suivants :

Après une légère poussée thermique dans les 48 heures qui suivirent l'inoculation, les 3 taurillons zébus n'ont pas réagi. Par contre, dès le $6^{\mathrm{e}}$ jour, les 2 veaux N'Dama commencèrent à présenter des

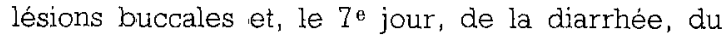
jetage et du larmoiement. La température avait dépassé 4105 dès le $4^{\circ}$ jour.

L'état de ces animaux d'épreuve empira progressivement : le taurin inoculé au broyat de rate devait succomber au bout du 9 e jour, tandis que celui qui avait reçu du sang du coeur mourait le $13^{\mathrm{e}}$ jour. Les lésions nécropsiques relevées sur leurs cadavres ne firent que confirmer les symptômes pestiques constatés sur ces deux malades.

Ainsi donc, le diagnostic de peste bovine élait définitivement établi, la réaction avortée constatée sur les zébus étant conforme à ce que nous savons de la résistance naturelle de cette espèce au virus pestique.

\section{CONSIDÉRATIONS ÉPIDÉMIOLOGIQUES}

Malgré les apparences, il ne semble pas impossible que le premier phacochère mort ait été victime de l'épizootie; son état de moindre résistance et son incapacité à se défendre pouvant expliquer qu'au sein d'un troupeau essentiellement querelleur, il ait pu recevoir un coup violent qui provoqua la mort par hémorragie interne.

Cela étant, il est intéressant de rechercher quelle a pu être l'origine, en vérité assez obscure, de cette maladie.

Le troupeau vivait dans un vaste enclos grillagé, à l'abri d'animaux susceptibles de le contaminer. Aucun cas de peste bovine n'existait à notre connaissance dans le voisinage immédiat du parc de l'IFAN, situé d'ailleurs à l'écart de la ville, dans un site rocheux non fréquenté des troupeaux de bovins.

Aucun phacochère nouveau n'avait été introduit dans l'enclos.

Bien que cette explication nous répugne par sa facilité, nous devons admettre que les oiseaux ont été les vecteurs de la maladie.

En effet Passéridés, Milans et Vautours abondent dans le voisinage et sont particulièrement nombreux aux heures de distribution de la nourriture qu'ils viennent disputer aux pensionnaires de IIFAN.

La source d'infection, si elle n'existait pas aux portes mêmes de l'établissement, était cependant assez répandue dans les environs de Bamako, au même titre que sur l'ensemble du territoire de la Fédération où la peste bovine sévit notoirement à l'état enzootique.

Cependant, les antilopes, dont le parc n'est séparé de celui des phacochères que par un passage de quelques mètıes, ont échappé au mal, et ceci pose un nouveau problème malaisé à résoudre.

Quoi qu'il en soit, cet épisode pathologique aux conséquences sévères nous a paru mériter d'être signalé. 